\title{
Preparation of dissolving pulp from oil palm empty fruit bunch by prehydrolysis soda-anthraquinone cooking method
}

\author{
Harsono Harsono ${ }^{1,2} \cdot$ Agusta Samodra Putra $^{1} \cdot$ Roni Maryana $^{1} \cdot$ \\ Andri Taufick Rizaluddin ${ }^{1}$ Y Yin Ying H'ng ${ }^{1}$ Akiko Nakagawa-izumi ${ }^{1}$. \\ Hiroshi Ohi ${ }^{1}$
}

Received: 10 July 2015/Accepted: 23 October 2015/Published online: 18 November 2015

(C) The Japan Wood Research Society 2015

\begin{abstract}
This study aimed to investigate the production of dissolving pulp (DP) from empty fruit bunch (EFB) of oil palm (Elaeis guineensis) as a non-wood material using a combination of prehydrolysis, soda-anthraquinone (AQ) cooking, and elementary chlorine-free (ECF) or totally chlorine-free (TCF) bleaching. Prehydrolysis was performed for $90-180 \mathrm{~min}$ at $150{ }^{\circ} \mathrm{C}$. Subsequently, the prehydrolyzed EFB was subjected to several soda-AQ cooking conditions with active alkali (AA) dosages of 19, 20, and $21 \%$ at $160{ }^{\circ} \mathrm{C}$. The obtained pulps were bleached following ECF and TCF sequences with oxygen $(\mathrm{O})$, chlorine dioxide $\left(\mathrm{D}_{0}\right)$, extraction with peroxide $\left(\mathrm{E}_{\mathrm{p}}\right)$, chlorine dioxide $\left(\mathrm{D}_{1}\right)$, and peroxymonosulfuric acid $\left(\mathrm{P}_{\mathrm{sa}}\right)$ stages. The results showed that the optimal duration of the prehydrolysis was $180 \mathrm{~min}$, while the best AA dosage of the soda-AQ cooking was $20 \%$. The determination of pulp qualities showed that ECF bleaching with the $\mathrm{P}_{\mathrm{sa}}-\mathrm{D}_{0}-\mathrm{E}_{\mathrm{p}}-$ $\mathrm{D}_{1}$ sequence reached $90.7 \%$ ISO brightness, $8.5 \mathrm{cP}$ viscosity, $98.6 \% \alpha$-cellulose, and that TCF bleaching with the $\mathrm{O}-\mathrm{P}_{\mathrm{sa}}-\mathrm{E}_{\mathrm{p}}-\mathrm{P}_{\mathrm{sa}}-\mathrm{E}$ sequence attained $81.6 \%$ ISO brightness, $9.6 \mathrm{cP}$ viscosity, and $95.9 \% \alpha$-cellulose. The results indicated a promising potential of EFB for DP production.
\end{abstract}

Hiroshi Ohi

oi.hiroshi.gm@u.tsukuba.ac.jp

1 Graduate School of Life and Environmental Sciences, University of Tsukuba, 1-1-1 Tennodai, Tsukuba, Ibaraki 305-8572, Japan

2 Center of Agricultural Engineering Research and Development, Ministry of Agriculture of Indonesia, Jakarta, Indonesia
Keywords Oil palm - Empty fruit bunch $\cdot$ Sodaanthraquinone cooking . Chlorine-free bleaching . Dissolving pulp

\section{Introduction}

Vegetable oil from oil palm (Elaeis guineensis) is one of the most important commercial products in Indonesia, which produces about 25 million tons of crude palm oil (CPO) annually, with an average growth higher than $2 \%$ in 2012 [1]. In Indonesia, oil palm trees are located in rural areas, spread mostly on Sumatera and Kalimantan islands. In recent years, Indonesia has successfully encouraged the expansion of the crop in more remote locations on the islands of Kalimantan (Borneo), Sulawesi, and Papua. The Ministry of Agriculture of the Republic of Indonesia estimated the oil palm area of 22 plantations to be approximately 11 million hectares in 2013 [1,2]. The location of the palm oil plantations in Indonesia is shown in Fig. 1 [1, 3].

Palm oil mills separate CPO and palm kernel oil (PKO) as main products, leaving residues such as wastes of shells, fibers, fronds, palm kernel cake, and empty fruit bunch (EFB), which is the main by-product of the palm fruit. Palm oil is used in a wide variety of food products such as cooking oil, shortenings, and margarine, whereas PKO is a raw material in the production of non-food products including soaps, detergents, toiletries, cosmetics, and candles. EFB and fronds are expected to be further processed into paper and paperboard, while fibers and shells can be utilized as a boiler fuel to generate steam in palm oil mills. However, most of the residues are not utilized, and most of the EFBs are left rotting in the plantation site without further processing. 


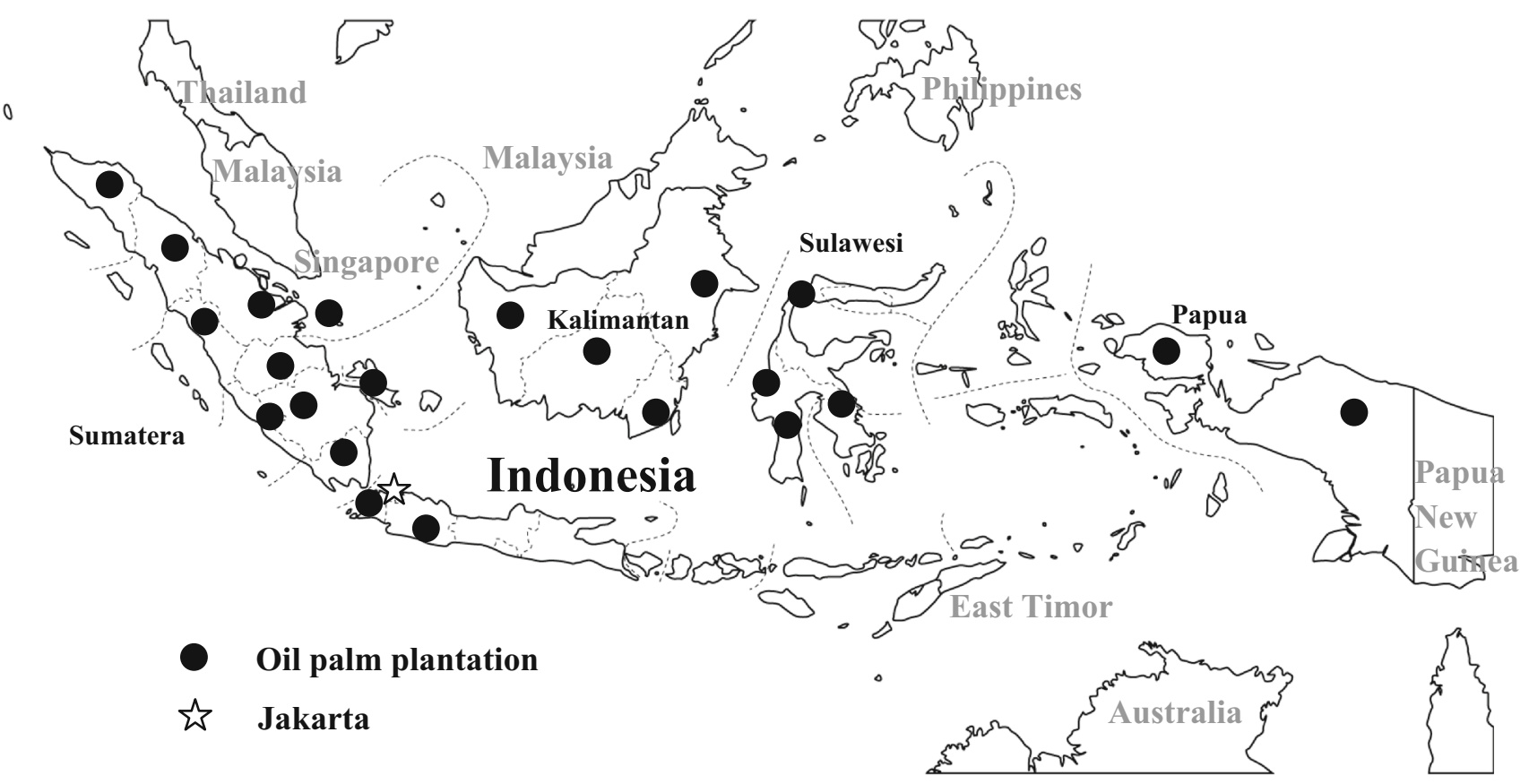

Fig. 1 Palm oil plantation in Indonesia $[1,3]$

The Food and Agriculture Organization of the United Nations estimated that the global production of CPO generated was 50 million tons per year, in 2012. Southeast Asia is the main contributor, with Indonesia and Malaysia accounting for 47 and $37 \%$, respectively. In the production of one $\mathrm{kg}$ of palm oil, approximately $4 \mathrm{~kg}$ of dry biomass is produced, of which one-third is EFB. Thus, the potency of EFB materials was about 30 million tons per year in Indonesia.

In 2003, the first pulp and paper mill using oil palmbased materials was set up by the Forest Research Institute Malaysia and a pulp and paper manufacturer (Borneo Advanced Sdn. Bhd.) located in East Malaysia (Sabah). In the paper mill, EFB is converted into pulp using the caustic soda technology [4]. However, as mentioned before, EFBs have not been optimally utilized until now. In practice, EFBs have been usually burned in palm oil mill incinerators, causing environmental pollution problems in nearby localities. The moisture content of fresh EFB is usually over $60 \%$; consequently, without drying, it is a poor fuel and presents considerable emission problems [5].

EFB is composed primarily of cellulose, hemicellulose, and lignin as a lignocellulosic material. Previous studies have reported that the amount of cellulose in EFB was estimated to be around 30-50\%, while hemicellulose and lignin contents were around $15-35 \%$ and $20-30 \%$, respectively [6], while lignin of EFB has not been isolated and its structural feature has not been clarified.

Dissolving pulp (DP) is used as a material for viscose rayon, cellophane, and other cellulose derivatives. It requires high-quality $\alpha$-cellulose with a pure degree (higher than $90 \%$ ), a relatively low content of hemicellulose, and an extremely low content (less than $0.05 \%$ ) of lignin. Several methods have been developed for producing DP. Prehydrolysis is one of the most important steps to remove hemicellulose and assist the separation of lignin from raw materials. Compared to kraft cooking, soda-anthraquinone (AQ) cooking as a sulfur-free cooking method is preferable and more suitable to cook non-woody materials, considering the environmental concerns. Andrade and Colodette [7] have reported on production of DP from sugarcane bagasse by adopting these processes.

Prehydrolysis followed by the soda cooking process has been proposed as a suitable preparation method for DP from EFB. In previous studies, the best conditions for prehydrolysis were found to be $170{ }^{\circ} \mathrm{C}$ for $60 \mathrm{~min}$, followed by soda cooking [8]. However, viscosity of the soda pulp was very low $(12-14 \mathrm{cP})$. The optimum variables for soda cooking were statistically analyzed to be $161{ }^{\circ} \mathrm{C}$ for 100 min with $26.1 \%$ of alkali level to attain a pulp with $31.2 \%$ of screened yield, 6.0 of kappa number, $96.9 \%$ of $\alpha$-cellulose, $16.1 \mathrm{cP}$ of viscosity, and $0.15 \%$ of ash content [9]. However, the viscosity level was not sufficiently high for the next bleaching, and brightness of the pulp was not shown in the previous study. On the other hand, total chlorine-free (TCF) bleaching methods were also proposed using oxygen $(\mathrm{O})$ bleaching for EFB soda pulp [10], ozone (Z) bleaching, and alkaline peroxide $(\mathrm{P})$ bleaching for the kraft pulp [11]. However, the brightness of O-bleached and Z-P-bleached pulps was not sufficiently high (67.1 and 
$73.9 \%$ ). Although O-Z-P bleaching for the prehydrolysis soda-AQ pulp has been proposed, there was neither experimental procedure nor results of final brightness in a previous study [12].

Compared with Z-P bleaching, we have proposed the application of peroxymonosulfuric acid $\left(\mathrm{P}_{\mathrm{sa}}\right)$ as a modification of the totally chlorine-free bleaching, and reported that the application of $\mathrm{P}_{\mathrm{sa}}$ demonstrated high effectiveness suggesting that $\mathrm{P}_{\mathrm{sa}}$ could be applied as an alternative to ozone [13]. The DP quality depends both on the properties of the raw materials and the cooking and bleaching processes. This study is aimed at determining first lignin and other chemical components of EFB raw materials, clarifying secondly the suitable conditions for preparing DP from EFB with the combination of prehydrolysis and sodaAQ cooking, followed by modified elementary chlorinefree (ECF) or TCF bleaching using $\mathrm{P}_{\mathrm{sa}}$ as alternative to ozone.

\section{Experimental}

\section{Raw materials and analysis of chemical composition}

EFB was obtained from a palm oil mill of PT. Perkebunan Nusantara VIII in Bogor, West Java, Indonesia. EFB was cut into $10-15 \mathrm{~cm}$ fiber fragments and dried to $8-10 \%$ of moisture content; the fibers of EFB were then further cut to a length between 0.2 and $1 \mathrm{~cm}$ with a laboratory disk mill for cooking. EFB materials were milled with a Wiley mill and sieved to retain particles of 40-80 mesh in size. They were kept at room temperature and air-dried. The milled materials were then soxhlet-extracted with acetone and $n$ hexane to determine the content of the extractives, according to the TAPPI Test Method: T204 cm-07 [14]. Meanwhile, air-dried pulp sheets were prepared to measure the pulp yield (as oven-dried) after cooking.

The acid-insoluble lignin (Klason lignin) content of the raw materials was determined using the method of Yoshihara et al. [15] with modified procedures as follows [16]: the prepared sample ( $0.5 \mathrm{~g}$, as oven-dried weight) was primarily hydrolyzed with $72 \%$ sulfuric acid for $2.5 \mathrm{~h}$ and further hydrolyzed with $4 \%$ sulfuric acid at $121{ }^{\circ} \mathrm{C}$ for $1 \mathrm{~h}$. The sample was then filtered to obtain the residue and filtrate with a glass filter (1 GP 16). The weight of the residue was measured as acid-insoluble lignin. The amount of acid-soluble lignin was determined according to UV spectrophotometry at the wavelength of $205 \mathrm{~nm}$ (TAPPI Test Method: T222 om-11 [17]). The amounts of glucose and xylose were determined from the 1000 times diluted filtrate by using ion chromatography according to the procedures described in a previous study [18]. The system using Dionex ICS 3000 ion chromatograph (Dionex,
Sunnyvale, CA, USA) consisted of a single pulp model (SP-1), an electrochemical detector (ED), an IonPac AS 7 column $(\phi 4 \mathrm{~mm} \times 250 \mathrm{~mm})$, an IonPac AS 7 guard column $(\phi 4 \mathrm{~mm} \times 50 \mathrm{~mm})$, and an auto sampler (AS).

The EFB materials were incinerated at $575{ }^{\circ} \mathrm{C}$ for $4 \mathrm{~h}$ to determine the ash content according to the TAPPI Test Method: T211 om-12 [19].

\section{Pyrolysis gas chromatography/mass spectrometry (Py-GC/MS)}

The EFB materials (150-200 $\mu \mathrm{g}$, as oven-dried weight) were used for the Py-GC/MS analysis. The suitable conditions for the Py-GC/MS analysis of lignin were chosen according to a previous study as follows [20]: JHP-5 (Japan Analytical Industry Co., Ltd., Tokyo, Japan) was used as the pyrolyzer. The pyrolysis temperature, pyrolysis time, pyrolyzer temperature, and transfer tube temperature were set at $500{ }^{\circ} \mathrm{C}, 4 \mathrm{~s}, 250{ }^{\circ} \mathrm{C}$, and $250{ }^{\circ} \mathrm{C}$, respectively. GCMS-QP 5050 A (Shimadzu Corporation, Kyoto, Japan) was used as the GC/MS system. An HP 1-MS $(30 \mathrm{~m} \times 0.25 \mathrm{~mm}$; film thickness: $0.25 \mu \mathrm{m})$ column was used with $n$-eicosane solution as the internal standard. The concentration of $n$-eicosane in ethyl acetate was $1 \mu \mathrm{g} / \mu \mathrm{L}$.

\section{Prehydrolysis and cooking}

EFB materials ( $35 \mathrm{~g}$, as oven-dried weight) were placed in a $300 \mathrm{~mL}$ steel reactor and subjected to prehydrolysis with $245 \mathrm{~mL}$ of distilled water for $90-180 \mathrm{~min}$ at $150{ }^{\circ} \mathrm{C}$. After prehydrolysis, a part $(140 \mathrm{~mL})$ of the prehydrolysis liquor (PHL) was removed. The liquor-to-solid ratio of prehydrolysis was $7 \mathrm{~mL} / \mathrm{g}$ for the treatment of PHL removal. On the other hand, EFB materials $(35 \mathrm{~g})$ were subjected to prehydrolysis with $105 \mathrm{~mL}$ of distilled water for 90-180 min at $150{ }^{\circ} \mathrm{C}$. After prehydrolysis, any PHL was not removed. The liquor-to-solid ratio of prehydrolysis was $3 \mathrm{~mL} / \mathrm{g}$ for the treatment of PHL non-removal. After prehydrolysis, the wet solid residue was subjected to soda-AQ cooking for $180 \mathrm{~min}$ at $160{ }^{\circ} \mathrm{C}$ with 19,20 , or $21 \%$ of active alkali (AA) dosages by adding $140 \mathrm{~mL}$ of fresh alkaline cooking liquor. AQ (SAQ: 1,4-dihydro-9,10-dihydroxyanthracene sodium salt, provided by Kawasaki Kasei Chemicals Ltd.) dosage and liquor-to-solid ratio were $0.1 \%$ and 7 , respectively.

\section{Bleaching sequences and conditions}

The following sequences and conditions are summarized with results in the Table. For a $\mathrm{D}_{0}-\mathrm{E}_{\mathrm{p}}-\mathrm{D}_{1}$ ECF bleaching sequence, prehydrolysis soda-AQ pulp (10 g, as oven-dried weight) was treated in a bag made of polyvinylidene chloride sheets with $\mathrm{ClO}_{2}$ at the pulp consistency (PC) of 
$10 \%$. After washing, the pulp was treated in a polyethylene bag with $\mathrm{NaOH}$ and $\mathrm{H}_{2} \mathrm{O}_{2}$, washed again, and treated in the polyvinylidene chloride bag with $\mathrm{ClO}_{2}$. For the $\mathrm{O}-\mathrm{P}_{\mathrm{sa}}-\mathrm{E}_{\mathrm{p}}-\mathrm{P}_{\mathrm{sa}}-\mathrm{E}$ TCF sequence, prehydrolysis sodaAQ pulp (10 g, as oven-dried weight) was oxygen (O) bleached at the PC of $30 \%$. Peroxymonosulfuric acid $\left(\mathrm{P}_{\mathrm{sa}}\right)$ was synthesized according to the previous procedure [13] by dropping $95 \%$ sulfuric acid (Wako Pure Chemical Industries, Ltd.) into $45 \%$ hydrogen peroxide aqueous solution (Mitsubishi Gas Chemical Company, Inc.) at $70{ }^{\circ} \mathrm{C}$. A target amount of $\mathrm{P}_{\mathrm{sa}}$ and a small amount of $\mathrm{NaOH}$ aqueous solution for adjusting to $\mathrm{pH} 3.0$ were added to the pulp suspension at the PC of $10 \%$ in a polyethylene bag.

\section{Evaluation of pulp qualities}

The contents of acid-insoluble lignin and acid-soluble lignin, and the carbohydrate composition were determined according to the methods mentioned previously. Kappa number, viscosity, brightness, and $\alpha$-cellulose were determined using the TAPPI Test Methods: T236 om-13 [21], T230 om-13 [22], T452 om-08 [23], and T203 cm-09 [24], respectively. The brightness (ISO) was measured using a Tokyo-Denshoku Digital Color Meter Model TC-1500 SX.

\section{Results and discussion}

\section{Chemical characteristics of EFB raw material}

As reported in Table 1, the contents of glucan (cellulose), xylan (hemicellulose), and total lignin (acid-insoluble and acid-soluble) for EFB raw material were 35.7, 20.1, and $27.6 \%$, respectively. The total of the extractives in the $n$ hexane and acetone solvents was $7.1 \%$. The Py-GC/MS analysis confirmed that EFB comprised guaiacyl and syringyl types of lignin, and that EFB raw material still contained palmitic acid and oleic acid as components, which are suggested to be originally derived from the palm oil of fresh fruit (Fig. 2).

We compared the chemical composition of EFB with those of other two lignocellulosic materials: sugarcane bagasse as an agricultural residue biomass [25] and Acacia mearnsii wood as a plantation hardwood for a resource of paper production [13]. The comparison suggested that EFB is a high-potential resource, revealing a high content of total carbohydrate (glucan and xylan) of $55.8 \%$, similar to those of sugarcane bagasse $(62.0 \%)$ and A. mearnsii $(58.6 \%)$ for paper and paperboard. The key advantage of EFB as a potential resource for DP production in Indonesia is provided by its considerably more abundant stock than bagasse, which has been estimated to reach only around 2.9 million tons annually [25].

\section{Application of prehydrolysis and soda-AQ cooking to EFB}

The yields of DPs from woods (given by acid sulfite, multistage sulfite, and prehydrolysis kraft methods) are generally between 35 and $40 \%$ [26]. The prehydrolysis process is preferred for preparing DPs from hardwoods with an $\alpha$-cellulose content higher than $90 \%$. In this study, effects of prehydrolysis treatments of EFB were thoroughly evaluated based on the delignification of the soda-AQ cooking process.

As shown in Table 1, a kappa number and a pulp yield of EFB prehydrolysis soda-AQ pulp were 9.6 and $31.1 \%$, respectively, which were significantly lower than those soda-AQ pulp (17.3 and $41.8 \%$, respectively). Differences in kappa numbers and yields between the two pulps cannot be explained by the differences in the amount of lignin and carbohydrates before and after the prehydrolysis. Previous studies $[27,28]$ suggested that prehydrolysis with water may diminish the linkages between lignin and

Table 1 Chemical composition of empty fruit bunch (EFB) raw material and pulps

\begin{tabular}{|c|c|c|c|c|c|c|c|c|c|}
\hline & $\begin{array}{l}\text { Kappa } \\
\text { number }\end{array}$ & $\begin{array}{l}\text { Yield } \\
\text { (\% bas }\end{array}$ & $\begin{array}{l}\text { Acid-insoluble (soluble) } \\
\text { lignin } \\
\text { ed on raw material) }\end{array}$ & Glucan & Xylan & $\begin{array}{l}\text { Other } \\
\text { sugars }\end{array}$ & Extractive & Ash & Unknown \\
\hline Raw material & - & - & $24.6(3.0)$ & 35.7 & 20.1 & 1.6 & 7.1 & 5.5 & 2.4 \\
\hline Prehydrolysate & - & 8.3 & $0.43(0.67)$ & 0.17 & 1.8 & 0.87 & - & 1.6 & 2.8 \\
\hline Soda-AQ pulp ${ }^{a}$ & 17.3 & 41.8 & - & - & - & - & - & - & - \\
\hline $\begin{array}{l}\text { Prehydrolysis }{ }^{\mathrm{b}} \text { soda-AQ } \\
\text { pulp }^{\mathrm{a}}\end{array}$ & 9.6 & 31.1 & $0.9(0.2)$ & 22.4 & 4.1 & - & - & 0.4 & 3.1 \\
\hline $\begin{array}{l}\text { Acacia prehydrolysis kraft } \\
\text { pulp }^{c}\end{array}$ & 13.2 & 45.2 & $0.7(0.4)$ & 39.2 & 4.3 & - & - & 0.1 & 0.5 \\
\hline
\end{tabular}

\footnotetext{
${ }^{\text {a }}$ Cooking temperature and time: $160{ }^{\circ} \mathrm{C}$ and 180 min, active alkali dosage: $20 \%$

b Prehydrolysis temperature and time: $150{ }^{\circ} \mathrm{C}$ and $180 \mathrm{~min}$

c Acacia mearnsii: Ref. [13]
} 
Fig. 2 Total ion chromatogram of pyrolysis products of raw material by pyrolysis-gas chromatography/mass spectrometry (Py-GC/MS)

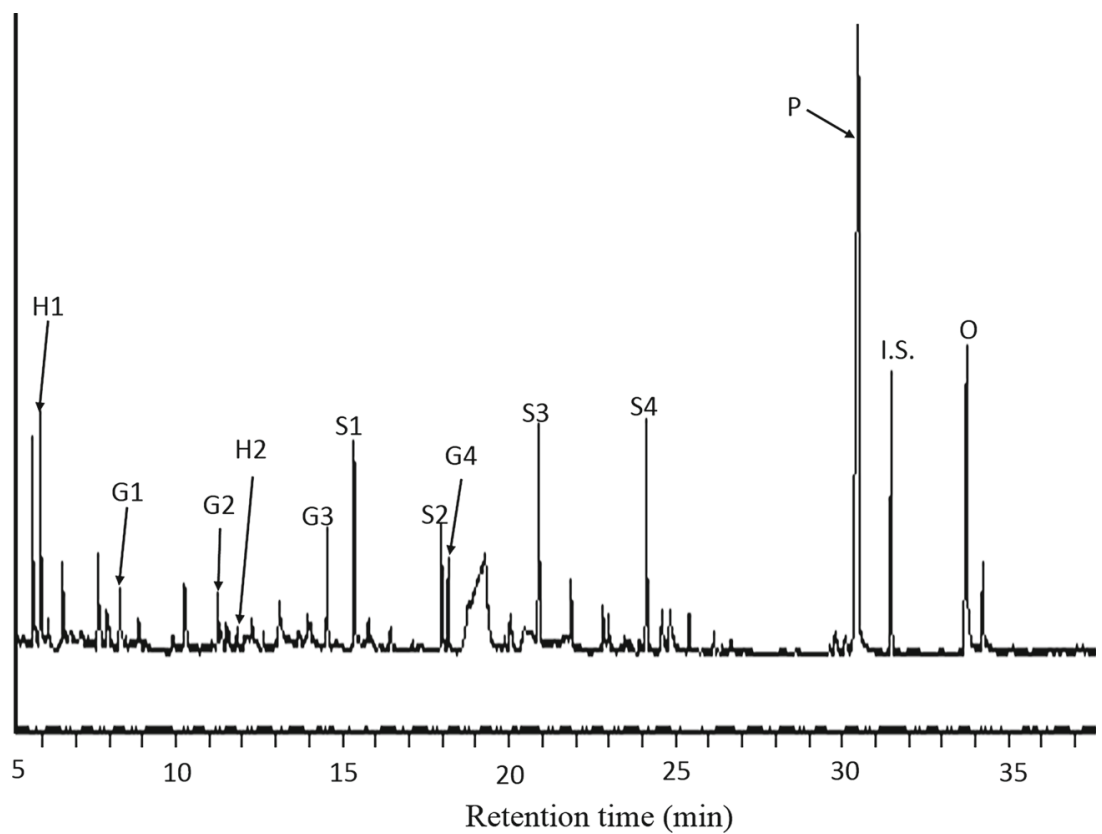

Legend:

\begin{tabular}{llll}
\hline Peaks & Products & Main ions, $m / z$ (relative intensity \%) & $\begin{array}{l}\text { Retention } \\
\text { time (min) }\end{array}$ \\
\hline H1 & Phenol & $94\left(\mathrm{M}^{+}, 100\right), 66(38)$ & 5.9 \\
G1 & Guaiacol & $124\left(\mathrm{M}^{+}, 83\right), 109(100)$ & 8.3 \\
G2 & 4-Methylguaiacol & $138\left(\mathrm{M}^{+}, 100\right), 123(93), 95(42), 77(22)$ & 11.3 \\
H2 & 4-Vinylphenol & $120\left(\mathrm{M}^{+}, 100\right), 91(55), 65(23), 43(25)$ & 12.3 \\
G3 & 4-Vinylguaiacol & $150\left(\mathrm{M}^{+}, 100\right), 135(83), 107(34), 77(36)$ & 14.5 \\
S1 & Syringol & $154\left(\mathrm{M}^{+}, 100\right), 139(55), 111(26), 93(33)$ & 15.3 \\
S2 & 4-Methylsyringol & $168\left(\mathrm{M}^{+}, 100\right), 153(49), 125(27), 107(16)$ & 18.0 \\
G4 & trans-Isoeugenol & $164\left(\mathrm{M}^{+}, 100\right), 149(35), 131(24), 103(22)$ & 18.2 \\
S3 & 4-Vinylsyringol & $180\left(\mathrm{M}^{+}, 100\right), 165(40), 137(32), 122(14)$ & 20.9 \\
S4 & trans-4-Prophenylsyringol & $194\left(\mathrm{M}^{+}, 100\right), 179(18), 151(13), 131(18)$ & 24.1 \\
P & Palmitic acid & $256\left(\mathrm{M}^{+}\right), 239,227,213$ & 30.4 \\
I.S. & $n$-Eicosane & $282\left(\mathrm{M}^{+}\right), 269,253,238$ & 31.5 \\
O & Oleic acid & $282\left(\mathrm{M}^{+}\right), 264,247,235$ & 33.7 \\
\hline
\end{tabular}

carbohydrates, and that the dissolution of hemicelluloses would also create some holes in the cell walls of the material, resulting in an efficient treatment in the subsequent process.

Table 1 presents the chemical composition of EFB and acacia pulp as a reference. The EFB materials had a relatively high ash content. The main elements in the EFB ash are reported to be potassium, calcium, and silica, with a significant amount of chlorine and sulfur [29]. The ash content decreased after cooking from $5.5 \%$ of the EFB material to $0.4 \%$ of the prehydrolysis soda-AQ pulp.
Compared with the acacia wood, the contents of lignin, xylan, and ash of the EFB raw material were high, and therefore the prehydrolysis conditions for EFB were necessary to be intensified from these for acacia.

\section{Effect of prehydrolysis time}

We discuss secondly the suitable conditions for preparing DP from EFB with the combination of prehydrolysis and soda-AQ cooking, because the prehydrolysis condition should have some effects on the following delignification 
Table 2 Effects of prehydrolysis and active alkali on soda-anthraquinone (AQ) cooking of EFB

\begin{tabular}{lllll}
\hline Prehydrolysis $^{\mathrm{a}}$ time $(\mathrm{min})$ & Active alkali $^{\mathrm{b}}(\%)$ & Kappa number & Pulp yield $(\%)$ & Viscosity $\left(\mathrm{cP}^{\mathrm{c}}\right)$ \\
\hline 90 & 19 & 17.5 & 37.3 & 17.5 \\
120 & 19 & 14.6 & 36.5 & 19.7 \\
150 & 19 & 11.5 & 35.0 & 20.0 \\
180 & 19 & 10.7 & 33.5 & 20.2 \\
90 & 20 & 13.9 & 37.1 & 20.8 \\
120 & 20 & 11.2 & 35.8 & 21.0 \\
150 & 20 & 10.3 & 33.4 & 21.8 \\
180 & 20 & 9.6 & 31.1 & 23.1 \\
90 & 21 & 13.0 & 37.1 & 19.5 \\
120 & 21 & 11.1 & 34.9 & 20.9 \\
150 & 21 & 10.2 & 31.7 & 22.4 \\
180 & 21 & 9.4 & 29.0 & 22.8 \\
\hline
\end{tabular}

${ }^{a}$ Prehydrolysis temperature: $150{ }^{\circ} \mathrm{C}$

b Soda-AQ cooking temperature: $160{ }^{\circ} \mathrm{C}$

c Centipoise

and hemicellulose dissolution, while the prehydrolysis does not cause delignification and complete dissolution of hemicellulose during prehydrolysis.

As confirmed in Table 2, the extension of prehydrolysis period assisted the decrease of the kappa number and pulp yield. Prehydrolysis for 180 min followed by soda-AQ cooking with $20 \%$ of AA dosage was selected as the optimum condition, as it resulted in a kappa number lower than 10. Thus, it was expected to give a slightly higher pulp yield than that obtained after $150 \mathrm{~min}$ of prehydrolysis and more than $21 \%$ of AA dosage in the cooking. Further addition of AA was shown to have no significant effect on the kappa number decrement while resulting in a pulp yield decrement.

Interestingly, the prehydrolysis condition for $180 \mathrm{~min}$ followed by soda-AQ cooking with $20 \%$ of AA dosage

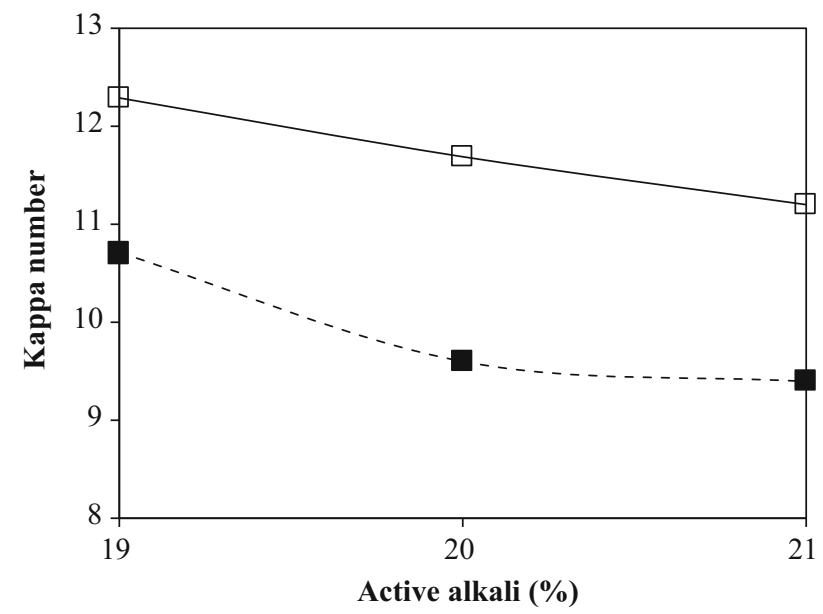

Fig. 3 Effect of prehydrolysis liquor (PHL) removal on kappa number of soda-anthraquinone (AQ) pulp. Empty square non-removal of PHL; filled square removal of PHL resulted in the highest viscosity of $23.1 \mathrm{cP}$ with a kappa number of 9.6 and pulp yield of $31.1 \%$. Further addition of AA was shown to result in a decrement of viscosity. The optimum kappa number with a suitable viscosity will provide an advantage in the following bleaching step.

\section{Effect of PHL removal}

As shown in Fig. 3, the removal of PHL clearly affected the decrement of the kappa number. Moreover, Figs. 3, 4, and 5 show that the PHL removal generated lower pulp yields, kappa numbers, and viscosities than the PHL nonremoval at the same AA dosages. We have reported that the prehydrolysis treatment could remove a part of xylan and a small part of lignin from wood into the PHL [13].

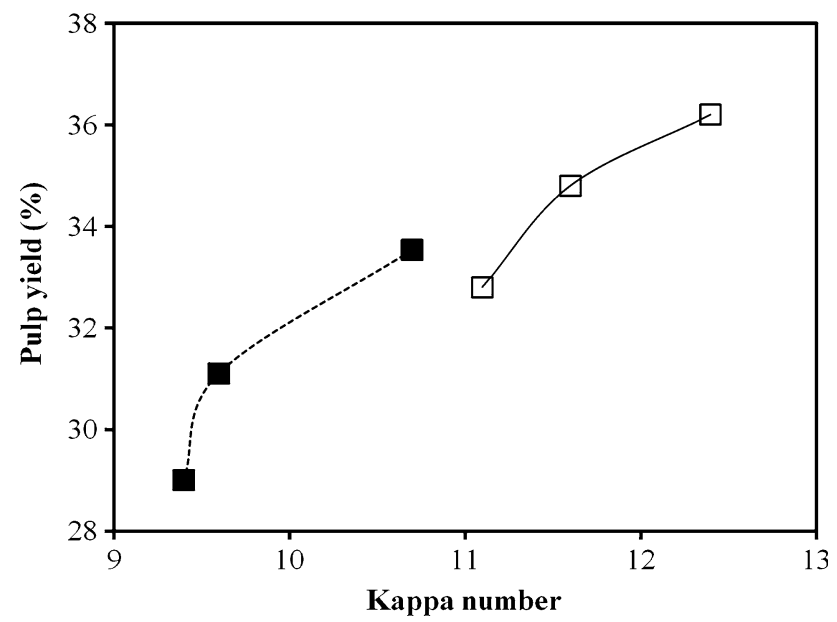

Fig. 4 Relationship between kappa number and pulp yield of sodaAQ pulp with PHL removal. Empty square non-removal of PHL; filled square removal of PHL 


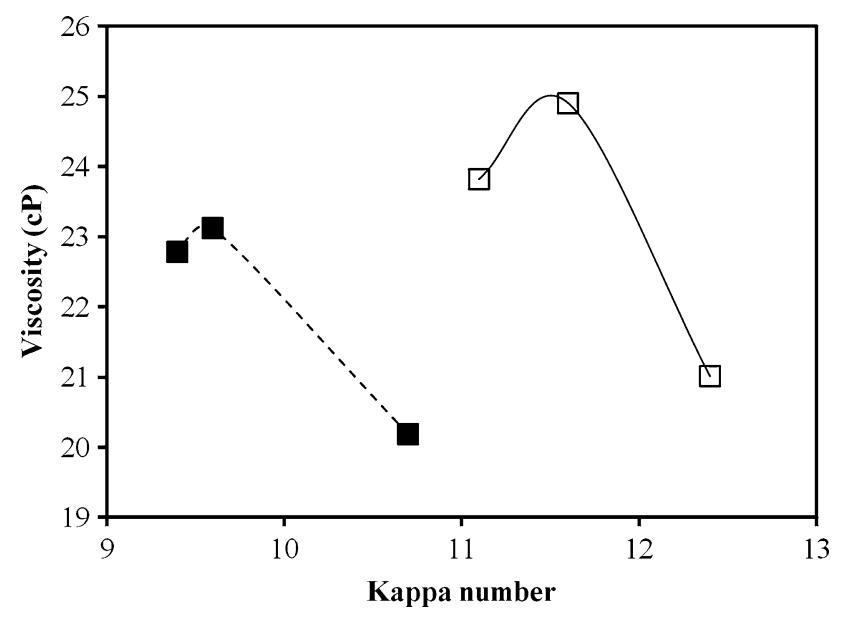

Fig. 5 Relationship between kappa number and viscosity of soda-AQ pulp with PHL removal. Empty square non-removal of PHL; filled square removal of PHL

Therefore, the soda-AQ delignification might be affected by the presence of organic compounds such as a part of xylan and lignin fraction as well as acetic acid in the PHL. The presence of acetic acid also decreased the $\mathrm{pH}$ of the non-removal PHL, thus causing a more alkaline consumption during the soda-AQ delignification.

Generally, saving chemicals of active alkali results in higher pulp yield and kappa number (Fig. 4), and would result in higher pulp viscosity. However, pulps with the highest viscosities were obtained at $20 \%$ of AA dosage in both cases of the PHL removal and non-removal (Fig. 5). As mentioned before, this is a very interesting behavior. Further addition of AA to obtain a kappa number lower than 10 should result in a further decrement of pulp yield and viscosity in the case of the PHL non-removal. These results suggested that the PHL removal process was preferred.

Pulp with a kappa number of 9.6 and viscosity of 23.1 cP was obtained after 180 min of prehydrolysis and sodaAQ delignification with AA dosage of $20 \%$. The increment of AA dosage causes more degradation of hemicellulose (xylan) than cellulose (glucan), because xylan is more sensitive to alkaline reaction. We reported carbohydrate composition (glucan and xylan contents) of a pulp obtained by AA $20 \%$ as a representative of the three pulps by AA 19, 20, and $21 \%$ in Table 1 . The AA dosage of $20 \%$ was found to be optimal to maintain the viscosity level. This phenomenon is probably caused by a higher extent of hemicellulose degradation which increases the cellulose ratio than that of the treatment with AA dosage of $19 \%$, because viscosity of cellulose is generally higher than that of xylan. However, for an AA dosage higher than $21 \%$, cellulose degradation should start and thus cause the viscosity decrement.

\section{Effect of bleaching sequence}

Pulp with a kappa number of 9.6 and viscosity of $23.1 \mathrm{cP}$ was treated with several bleaching sequences. As shown in Table 3, pulps with sufficient levels of viscosity and $\alpha$ cellulose content were obtained by three sequences. Brightnesses were 89.2 and $90.7 \%$ ISO for a conventional and a modified ECF sequences, respectively. Although Sharma et al. [30] recently reported on a pilot process of EFB soda-AQ cooking for ECF bleaching, we obtained higher brightness pulps with less dosage of $\mathrm{ClO}_{2}$ in this study. According to the Indonesian National Standard (SNI Standard) [31], where $6.2 \mathrm{cP}$ viscosity, $94 \%$-cellulose, and $88 \%$ ISO brightness are required as minimum levels

Table 3 Viscosity, brightness, and $\alpha$-cellulose of bleached pulp

\begin{tabular}{|c|c|c|c|c|}
\hline \multicolumn{2}{|c|}{ Bleaching sequence } & Viscosity (cP) & Brightness $\left(\% \mathrm{ISO}^{\mathrm{a}}\right)$ & $\alpha$-Cellulose $(\%)$ \\
\hline \multicolumn{5}{|c|}{ ECF bleaching sequence } \\
\hline \multicolumn{2}{|c|}{$\mathrm{D}_{0}-\mathrm{E}_{\mathrm{p}}-\mathrm{D}_{1}$} & 10.3 & 89.2 & 98.2 \\
\hline \multicolumn{2}{|c|}{$\mathrm{P}_{\mathrm{sa}}-\mathrm{D}_{0}-\mathrm{E}_{\mathrm{p}}-\mathrm{D}_{1}$} & 8.5 & 90.7 & 98.6 \\
\hline \multicolumn{5}{|c|}{ TCF bleaching sequence } \\
\hline \multicolumn{2}{|c|}{$\mathrm{O}-\mathrm{P}_{\mathrm{sa}}-\mathrm{E}_{\mathrm{p}}-\mathrm{P}_{\mathrm{sa}}-\mathrm{E}$} & 9.6 & 81.6 & 95.9 \\
\hline \multicolumn{5}{|c|}{ Bleaching conditions } \\
\hline $\mathrm{D}_{0}$ & Chlorine dioxide & \multicolumn{3}{|c|}{$\mathrm{ClO}_{2}$ dosage: kappa factor $0.30(2.9 \%), 60 \mathrm{~min}, 70^{\circ} \mathrm{C}, \mathrm{pH} 3.4, \mathrm{PC}^{\mathrm{b}}: 10 \%$} \\
\hline $\mathrm{P}_{\mathrm{sa}}$ & Peroxymonosulfuric acid & \multicolumn{3}{|c|}{$\mathrm{P}_{\mathrm{sa}}$ dosage: $0.2 \%, 60 \mathrm{~min}, 70^{\circ} \mathrm{C}, \mathrm{pH} 3.0, \mathrm{PC}: 10 \%$} \\
\hline $\mathrm{E}_{\mathrm{p}}$ & Extraction with peroxide & \multicolumn{3}{|c|}{$\mathrm{NaOH}$ dosage: $1 \%, \mathrm{H}_{2} \mathrm{O}_{2}$ dosage: $1.4 \%, 60 \min , 70^{\circ} \mathrm{C}, \mathrm{PC}: 10 \%$} \\
\hline $\mathrm{D}_{1}$ & Chlorine dioxide & \multicolumn{3}{|c|}{$\mathrm{ClO}_{2}$ dosage: $0.5 \%, 60 \min , 70{ }^{\circ} \mathrm{C}, \mathrm{PC}: 10 \%$} \\
\hline $\mathrm{O}$ & Oxygen & \multicolumn{3}{|c|}{ Oxygen pressure: $0.5 \mathrm{MPa}, \mathrm{NaOH}$ dosage: $1 \%, 60 \mathrm{~min}, 115{ }^{\circ} \mathrm{C}, \mathrm{PC}: 30 \%$} \\
\hline $\mathrm{E}$ & Extraction & \multicolumn{3}{|c|}{$\mathrm{NaOH}$ dosage: $1 \%, 60 \min , 70^{\circ} \mathrm{C}, \mathrm{PC}: 10 \%$} \\
\hline
\end{tabular}

\footnotetext{
${ }^{a}$ International Organization for Standardization
}

b Pulp consistency 
for rayon, these results indicate a potential for the production of DP from EFB by using a combination of prehydrolysis, soda-AQ cooking, and the modified ECF bleaching.

For the TCF bleaching sequence, the oxygen delignification should be the first stage of the sequence, as it has the ability to delignify and increase the pulp brightness without substantial reduction in pulp yield, viscosity, and $\alpha$-cellulose. Although the target brightness of $88 \%$ ISO could not be reached for the TCF bleaching sequence, the brightness level above $81.6 \%$ ISO still showed a potential for TCF bleaching application to EFB pulp.

\section{Conclusions}

The removal of PHL during the prehydrolysis process was preferred for an effective soda-AQ delignification of EFB, and a pulp with a lower kappa number and lower hemicellulose content could be produced. The prehydrolysis for 180 min followed by soda-AQ cooking with $20 \%$ of AA dosage was selected as the optimum condition, as it resulted in a kappa number lower than 10 and a higher viscosity. A brightness level higher than $88 \%$ ISO brightness was obtained by ECF sequences with sufficient levels of viscosity and $\alpha$-cellulose. The sequence of $\mathrm{P}_{\mathrm{sa}}-\mathrm{D}_{0^{-}}$ $\mathrm{E}_{\mathrm{p}}-\mathrm{D}_{1}$ can reach brightness of $90.7 \%$ ISO, viscosity of 8.5 $\mathrm{cP}$, and a-cellulose of $98.6 \%$, which were satisfied with the Indonesian standard for rayon. The production of DP from EFB with the combination of prehydrolysis, soda-AQ cooking, and a modified ECF bleaching was demonstrated. TCF bleaching sequence still showed a potential for application, although the target brightness was not obtained.

\section{References}

1. Statistic Indonesia (2014) Production of estates by province of crop (thousand tons) 2007-2013. www.bps.go.id/linkTabelStatis/ view/id/1672. Accessed 23 Apr 2015

2. Ministry of Agriculture of Indonesia (2014) Area, production and productivity estate crops in Indonesia. www.pertanian.go.id/Indi kator/tabel-3-prod-lsareal-prodvitas-bun.pdf. Accessed $23 \mathrm{Apr}$ 2015

3. The Geospatial Information Agency (2015) www.bakosurtanal. go.id/assets/download/nkri/NKRI_2.5_jt.jpg. Accessed 23 Apr 2015

4. Pooja S, Othman S, Rokia H, Leh CP, Rajeev PS (2013) Using biomass residues from oil palm industry as a raw material for pulp and paper industry: potential benefits and threat to the environment. Environ Dev Sustain 15:367-383

5. Sulaiman F, Abdullah N, Gerhauser H, Shariff A (2011) An outlook of Malaysian energy, oil palm industry and its utilization of wastes as useful resources. Biomass Bioenerg 35:3775-3786
6. Yunos NSHM, Baharuddin AS, Yunos KFM, Hafid HS, Busu Z, Mokhtar MN, Sulaiman A, Som AM (2015) The physicochemical characteristics of residual oil and fibers from oil palm empty fruit bunches. Bioresources 10:14-29

7. Andrade MF, Colodette JL (2014) Dissolving pulp production from sugar cane bagasse. Ind Crop Prod 52:58-64

8. Wan Rosli WD, Leh CP, Zainuddin Z, Tanaka R (2004) Effects of prehydrolysis on the production of dissolving pulp from empty fruit bunches. J Trop For Sci 16:343-349

9. Wan Rosli WD, Leh CP, Zainuddin Z, Tanaka R (2003) Optimisation of soda pulping variables for preparation of dissolving pulps from oil palm fibre. Holzforschung 57:106-113

10. Leh CP, Wan Rosli WD, Zainuddin Z, Tanaka R (2008) Optimisation of oxygen delignification in production of totally chlorine-free cellulose pulps from oil palm empty fruit bunch fibre. Ind Crop Prod 28:260-267

11. Tanaka R, Wan Rosli WD, Magara K, Ikeda T, Hosoya S (2004) Chlorine-free bleaching of kraft pulp from oil palm empty fruit bunches. Japan Agric Res Q 39:275-279

12. Muhammad Djuned F, Asad M, Mohamad Ibrahim MN, Wan Rosli WD (2014) Synthesis and characterization of cellulose acetate from TCF oil palm empty fruit bunch pulp. Bioresources 9:4710-4721

13. Rizaluddin AT, Liu Q, Panggabean PR, Ohi H, Nakamata K (2015) Application of peroxymonosulfuric acid as a modification of the totally chlorine-free bleaching of acacia wood prehydrolysis-kraft pulp. J Wood Sci 61:292-298

14. T204 cm-07 (2007) Solvent extractives of wood and pulp. TAPPI, Atlanta GA, USA. www.tappi.org/Bookstore/StandardsTIPs/Standards/. Accessed 21 Apr 2015

15. Yoshihara K, Kobayashi T, Fujii T, Akamatsu I (1984) A novel modification of Klason lignin quantitative method. Jpn Tappi J 38:466-475

16. Ohi H, Ju Y, Kuroda K (1997) Structural analysis of lignin by pyrolysis-gas chromatography (VII) Conditions for acid hydrolysis of wood pulps and characteristics of acid-insoluble residues. Jpn Tappi J 51:1578-1586

17. T222 om-11 (2011) Acid-insoluble lignin in wood and pulp. TAPPI, Atlanta GA, USA. www.tappi.org/Bookstore/StandardsTIPs/Standards/. Accessed 21 Apr 2015

18. Tanifuji K, Takahashi S, Kajiyama M, Ohi H (2011) Advantage of acid sulfite cooking as process of bioethanol production. Jpn Tappi J 65:494-505

19. T211 om-12 (2012) Ash in wood, pulp, paper and paperboard. TAPPI, Atlanta GA, USA. www.tappi.org/Bookstore/StandardsTIPs/Standards/. Accessed 21 Apr 2015

20. Hasumi A, Nakagawa-Izumi A, Homma M, Ohi H, Nakamata K (2009) Structural micro-analysis of residual lignin in pulp by pyrolysis-GC mass-spectrometry. Jpn Tappi J 63:959-970

21. T236 om-13 (2013) Kappa number of pulp. TAPPI, Atlanta GA, USA. www.tappi.org/Bookstore/Standards-TIPs/Standards/. Accessed 21 Apr 2015

22. T230 om-13 (2013) Viscosity of pulp (capillary viscometer method). TAPPI, Atlanta GA, USA. www.tappi.org/Bookstore/ Standards-TIPs/Standards/. Accessed 21 Apr 2015

23. T452 om-08 (2008) Brightness of pulp, paper and paperboard (Directional reflectance at $457 \mathrm{~nm}$ ). TAPPI, Atlanta GA, USA. www.tappi.org/Bookstore/Standards-TIPs/Standards/. Accessed 21 Apr 2015

24. T203 cm-09 (2009) Alpha-, beta- and gamma-cellulose in pulp. TAPPI, Atlanta GA, USA. www.tappi.org/Bookstore/StandardsTIPs/Standards/. Accessed 21 Apr 2015

25. Maryana R, Oktaviani K, Tanifuji K, Ohi H (2014) Comparison between acid sulfite and soda-AQ delignification methods for effective bio-ethanol production from sugarcane bagasse and oil palm empty fruit bunch. Proceedings of Pan Pacific Conference 
of the Technical Associations of the Pulp and Paper Industry, 21-23 May 2014, Taiwan, Taiwan TAPPI

26. Alén R (2000) Basic chemistry of wood delignification. In: Stenius $\mathrm{P}$ (ed) Forest product chemistry (Papermaking science and technology, book 3). PI and TAPPI Press, Helsinki, p 61

27. Ma X, Huang L, Chen Y, Cao S, Chen L (2011) Preparation of bamboo dissolving pulp for textile production. Part 1. Study on prehydrolysis of green bamboo for producing dissolving pulp. Bioresources 6:1428-1439

28. Ma X, Huang L, Cao S, Chen Y, Luo X, Chen L (2012) Preparation of dissolving pulp from bamboo for textile applications. Part 2. Optimization of pulping conditions of hydrolyzed bamboo and its kinetics. Bioresources 7:1866-1875
29. Konsomboon S, Pipatmanomai S, Madhiyanon T, Tia S (2011) Effect of kaolin addition on ash characteristics of palm empty fruit bunch (EFB) upon combustion. Appl Energy 88(1):298-305

30. Sharma AK, Anupam K, Swaroop V, Lal PS, Bist V (2015) Pilot scale soda-anthraquinone pulping of palm oil empty fruit bunches and elemental chlorine free bleaching of resulting pulp. J Clean Prod 106:422-429

31. Standard Nasional Indonesia (SNI) 0938:2010 (2010) Pulp rayon (in Indonesian). National standard Agency of Indonesia (BSN), Jakarta, Indonesia, www.sisni.bsn.go.id/index.php?/sni_main/sni/ detail_sni/9701. Accessed 21 Oct 2015 